\title{
A Review on Colorectal Cancer
}

\author{
Maryam Bincy Thomas", S.K.Sharma, Lalit Singh \\ Sunder Deep Pharmacy College, Ghaziabad, UP, India-201001 \\ *Corresponding Author : maryambincythomas@gmail.com
}

Copyright (c) 2013 Horizon Research Publishing All rights reserved.

\begin{abstract}
Cancers of the colon and rectum are the second leading cause of cancer death. Fifty percent of the colorectal cancer occurs in either the lower (sigmoid) colon or the rectum and should be easy to detect at an early stage. The majority of the colon cancers are not inherited, but rather are considered sporadic, having developed from an accumulation of mutations throughout the course of a lifetime. The epidemiological risk factors for cancers, other than genetic risk factors, include dietary components, such as the amount of fat and fiber in the diet, intake of calcium, vitamins of the antioxidant class, NSAIDS such as aspirin and specific inhibitors of cyclo-oxygenase. The risk of colon cancer increases with age, the history of previous polyps or cancer, family history of cancer, history of long standing inflammatory bowel disease including ulcerative colitis and Crohn's disease. Colonoscopy plays an important role in the medical care of patients with colorectal cancer. It is generally used for both the diagnosis of different stages of colorectal cancer and the treatment of early colorectal cancers and its precursors.
\end{abstract}

Keywords Colorectal Cancer, Colonoscopy, Diagnosis, Treatment

\section{Introduction ${ }^{1,2}$}

Colon cancer is the most common type of gastrointestinal cancer which can be derived from either inherited or somatic genetic alterations that develop over the course of a lifetime. This type of cancer begins in the cells of the glandular structures in the inner layers of the colon and spreads first into the wall of the colon and potentially into the lymphatic system and the other organs. Colon cancer stems from colon polyps that turn cancerous, and individuals who develop polyps are at the highest risk of colon cancer.

The adenoma-carcinoma sequence refers to a traditional view that colorectal malignancies develop from adenomatous polyps and, indeed, a large amount of evidence has been accumulated indicating that carcinomas of the large intestine arise from pre-existing, premalignant lesions, especially when associated with dysplastic changes. However, only few adenomas actually develop invasive cancer (progressive adenomas), although every adenoma has the capacity of malignant evolution. Most adenomas stabilize their progression or even regress. In addition, the earliest phases of colorectal tumorigenesis presumably initiate in normal mucosa, with a disorder of cell replication and renewal, and with the appearance of clusters of enlarged crypts showing proliferative, biochemical, and biomolecular abnormalities. Although several lines of evidence indicate that carcinomas usually originate from pre-existing adenomas, this does not imply that all polyps undergo malignant changes, and does not exclude "de novo" carcinogenesis (i.e., the development of cancer from flat mucosa). Thus, defining progression risk of adenomas, even in the long-term follow-up, remains an ongoing research for which few good predictors are available.

\section{Epidemiology and Incidence Rates ${ }^{3-6}$}

Colorectal cancer (CRC) incidence and mortality rates vary markedly around the world. Globally, CRC is the third most commonly diagnosed cancer in males and the second in females, with over 1.2 million new cases and 608,700 deaths estimated to have occurred in 2008. Rates are substantially higher in males than in females. Colorectal cancer incidences and the mortality rates are highest in African American men and women. The rates among other major racial/ ethnic groups are lower than those among whites. Globally, the incidence of CRC varies over 10-fold. The highest incidence rates are in Australia and New Zealand, Europe and North America, and the lowest rates are found in Africa and South-Central Asia. In the United States, both the incidence and mortality have been slowly but steadily decreasing. Annually approximately 142,820 new cases of large bowel cancer are diagnosed, of which 102,480 are colon and the remainder rectal cancers. The colorectal cancer incidence rates by race, ethnicity and gender is illustrate in fig. 1.

According to the Rajiv Gandhi Cancer Institute and Research Centre, colorectal cancer is the sixth most prevalent cancer in India. Hospital based and population based data show that the incidence rates for rectal cancer is higher than colon cancer in all parts of India. However, the incidence rates of rectal cancer are disproportionately higher in rural India. Population based time trend studies show a 
rising trend in the incidence of CRC in India. Worrisome is the finding that the incidence rates of $\mathrm{CRC}$ in Indian immigrants to the United Kingdom and USA are much higher, suggesting that life styles and dietary habits are important in the causation of the CRC.

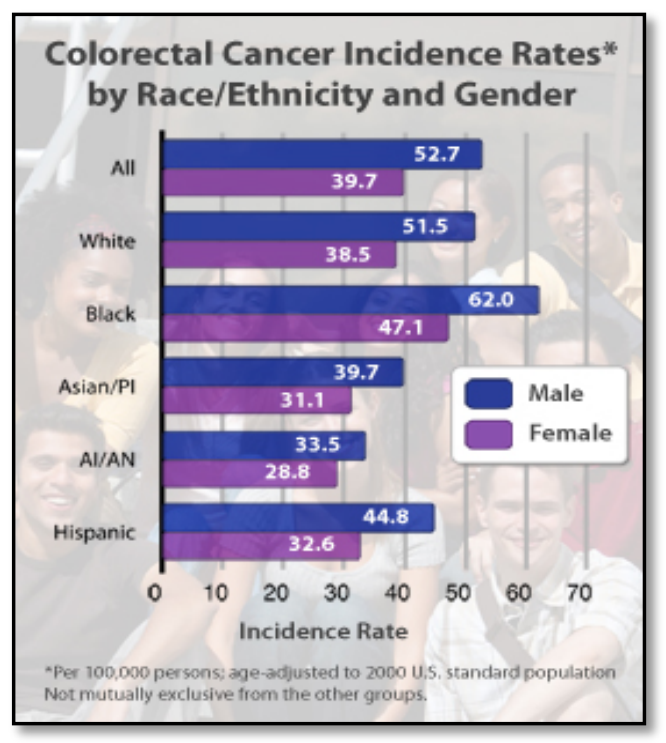

Figure 1. Colorectal cancer incidence rates by race/ ethnicity and gender

\section{Risk Factors}

There are many known factors that increase or decrease the risk of colorectal cancer; some of these factors are modifiable and the others are not.

- Non-Modifiable Risk Factors: The non-modifiable risk factors include family or personal history of colorectal cancer or adenomatous polyps, and a personal history of chronic inflammatory bowel diseases such as ulcerative colitis and Crohn's disease. $^{7}$ The non-modifiable risk factors of colorectal cancer are shown in table 1.

- Modifiable Risk Factors: The modifiable risk factors that are associated with colorectal cancers include physical activity, obesity, high consumption of red or processed meats, smoking, and alcohol consumption. Studies suggest that increasing calcium intake lowers the risk of colorectal cancer. It has also been found that the regular use of aspirin and other NSAIDS lower the risk of colorectal cancer and adenomatous polyp. A recent study revealed that a quarter of colorectal cancer could be avoided by following a healthy diet and lifestyle. ${ }^{8,9}$ The evidence of diet and lifestyle risk factors is shown in table 2 .

Table 1. Non-modifiable Risk Factors of Colorectal Cancer

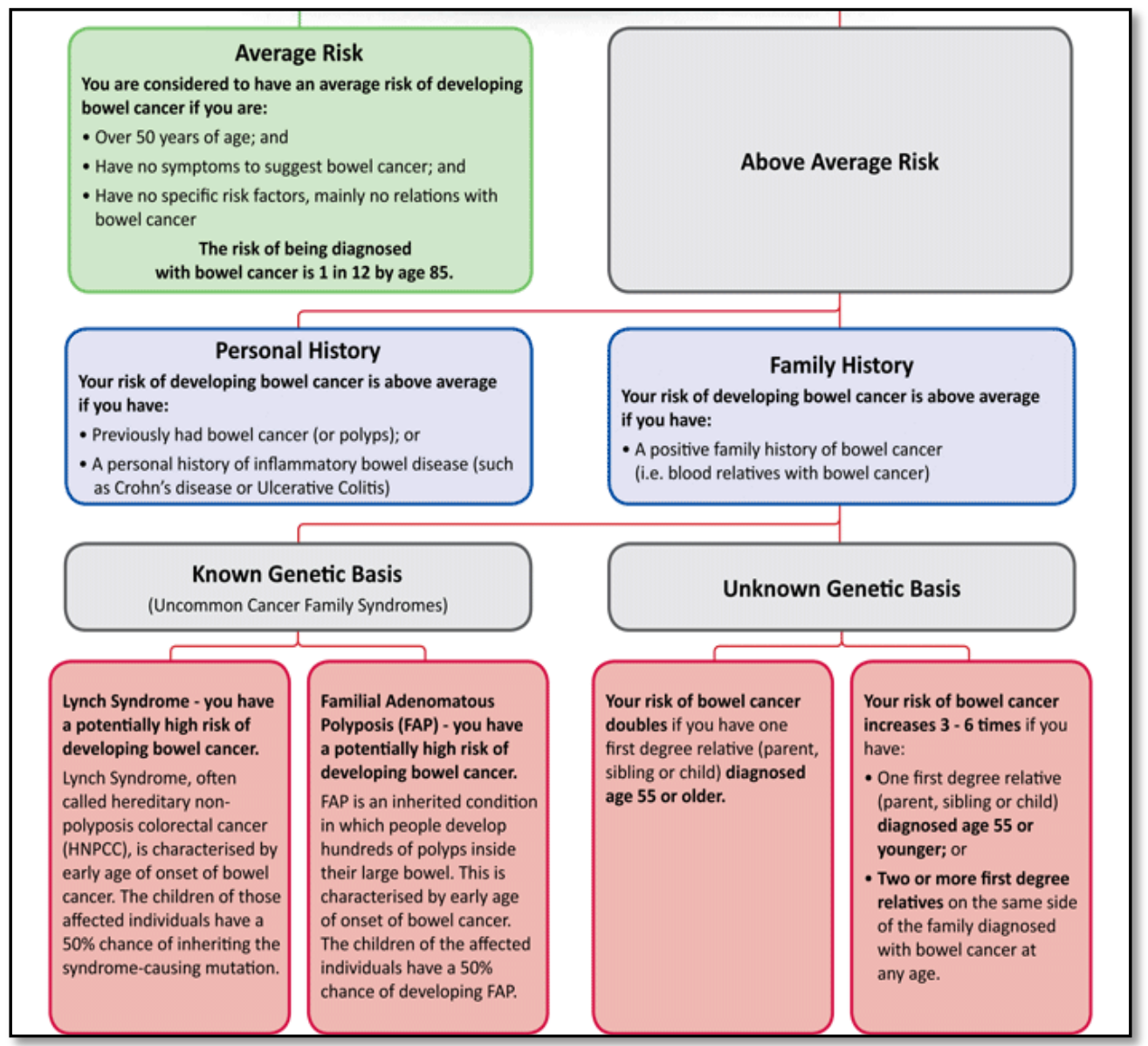


Table 2. Summary of evidence on diet and lifestyle risk factors for colorectal cancer

\begin{tabular}{|c|c|c|c|}
\hline & & Source of evidence & Summary points \\
\hline \multirow{11}{*}{$\begin{array}{l}\text { Convinc- } \\
\text { ing/rather } \\
\text { consistent }\end{array}$} & Red meat & $\begin{array}{l}\text { Meta-analysis of } \\
\text { observational studies } \\
\text { (mostly prospective } \\
\text { studies) }\end{array}$ & $\begin{array}{l}\text { Red and processed meat intake significantly increase CRC risk by } \sim 20 \% \text {, } \\
\text { contrasting highest vs. lowest intake, with a dose-response relationship } \\
\text { until } 140 \mathrm{~g} / \text { day; association is strong in men; frequency of consumption } \\
\text { may matter more than total amount consumed; avoid burned meat }\end{array}$ \\
\hline & Vitamin B6 & $\begin{array}{l}\text { Meta-analysis of } \\
\text { prospective studies }\end{array}$ & $\begin{array}{l}\text { Vitamin B6 intake (statistically nonsignificant) and blood PLP levels } \\
\text { (statistically significant) were inversely associated with CRC risk }\end{array}$ \\
\hline & \multirow{2}{*}{ Garlic } & Small randomized trial & $\begin{array}{l}\text { Significant suppression of adenoma in CRC patients with } 12 \text {-mo high-dose } \\
\text { of aged garlic extract; } 29 \% \text { reduction in developing new adenoma }\end{array}$ \\
\hline & & $\begin{array}{l}\text { Meta-analysis of } \\
\text { observational studies }\end{array}$ & $\begin{array}{l}\text { Approximately } 30 \% \text { reduction in } \mathrm{CRC} \text { risk, contrasting high vs. low } \\
\text { (16 g/wk average difference across studies) consumption of garlic }\end{array}$ \\
\hline & $\begin{array}{l}\text { Magne- } \\
\text { sium }\end{array}$ & $\begin{array}{l}\text { Meta-analysis of } \\
\text { large cohort studies }\end{array}$ & $\begin{array}{l}10 \% \text { risk reduction contrasting the highest vs. lowest category of } \\
\text { magnesium intake, with dose response }\end{array}$ \\
\hline & Alcohol & $\begin{array}{l}\text { Meta-analysis of } \\
60 \text { observational studies }\end{array}$ & $\begin{array}{l}\text { Significant increase in CRC risk with dose-response; } 21 \% \text { risk increase for } \\
\text { moderate drinkers }(2-3 \text { drink/d) and } 52 \% \text { risk increase for heavy drinkers } \\
(4+\text { drink/d), compared to never drinkers }\end{array}$ \\
\hline & Obesity & $\begin{array}{l}\text { Meta-analysis of } \\
31 \text { observational studies }\end{array}$ & $\begin{array}{l}\text { CRC risk increases by } 7 \%(4-10 \%) \text { with a } 2 \mathrm{~kg} / \mathrm{m}^{2} \text { increase in BMI; CRC } \\
\text { increases by } 4 \%(2-5 \%) \text { with a } 2-\mathrm{cm} \text { increase in waist circumference }\end{array}$ \\
\hline & $\begin{array}{l}\text { Physical } \\
\text { activity }\end{array}$ & $\begin{array}{l}\text { Meta-analyses of } \\
\text { observational studies }\end{array}$ & $\begin{array}{l}\text { Approximately } 20 \% \text { risk reduction, contrasting physically active } \\
\text { individuals vs. inactive }\end{array}$ \\
\hline & Smoking & $\begin{array}{l}\text { Meta-analyses of } 100+ \\
\text { observational studies }\end{array}$ & $\begin{array}{l}18 \% \text { risk elevation contrasting smokers } v s . \text { nonsmokers, with dose- } \\
\text { response; Risk may reduce immediately following cessation of smoking }\end{array}$ \\
\hline & \multirow{2}{*}{$\begin{array}{l}\text { Hormone } \\
\text { replace- } \\
\text { ment } \\
\text { therapy }\end{array}$} & $\begin{array}{l}\text { Meta-analysis of } \\
\text { observational studies }\end{array}$ & $\begin{array}{l}\text { A } 33 \% \text { risk reduction for recent users, compared to nonusers; Protective } \\
\text { effect may be short lived and disappear following cessation of use }\end{array}$ \\
\hline & & Randomized trial & $\begin{array}{l}\text { A } 44 \% \text { reduced CRC risk }(95 \% \mathrm{Cl}, 19-62 \%) \text {, comparing the } \mathrm{E}+\mathrm{P} \text { arm vs. } \\
\text { placebo arm }\end{array}$ \\
\hline \multirow{10}{*}{$\begin{array}{l}\text { Probable/ } \\
\text { less } \\
\text { consistent }\end{array}$} & \multirow{3}{*}{$\begin{array}{l}\text { Fruit and } \\
\text { vegetables } \\
\text { (Dietary } \\
\text { fiber) }\end{array}$} & Observational studies & $\begin{array}{l}\text { Many reported an inverse association but a few large cohort studies } \\
\text { reported null association }\end{array}$ \\
\hline & & $\begin{array}{l}\text { Meta-analysis of } \\
\text { large cohort studies }\end{array}$ & Inconsistent. The inverse association is weak, about $\sim 10 \%$ risk reduction \\
\hline & & Randomized trial & No association \\
\hline & \multirow{3}{*}{$\begin{array}{l}\text { Fruit and } \\
\text { vegetables } \\
\text { (folate) }\end{array}$} & Case-control study & $\begin{array}{l}\text { Minimal essential serum folate should be above } 8.0 \mathrm{ng} / \mathrm{mL} \text { for reduced risk } \\
\text { of developing colorectal adenoma }\end{array}$ \\
\hline & & Cohort studies & $\begin{array}{l}\text { Approximately } 40 \% \text { risk reduction contrasting highest } v s \text {. lowest quartile of } \\
\text { intake; both long-and short-term intake may reduce risk }\end{array}$ \\
\hline & & $\begin{array}{l}\text { Meta-analysis of } \\
\text { randomized or } \\
\text { pseudo-randomized trials }\end{array}$ & Evidence inconsistent; most meta-analyses reported null results \\
\hline & \multirow{4}{*}{$\begin{array}{l}\text { Fish and } \\
\text { Omega-3 } \\
\text { fatty acids } \\
\text { (FA) }\end{array}$} & Longitudinal cohort study & (Omega-3 FA) Significant risk reduction over 22-year follow-up \\
\hline & & Observational studies & (Fish) Evidence inconsistent \\
\hline & & $\begin{array}{l}\text { Meta-analysis of } \\
\text { observational studies }\end{array}$ & $\begin{array}{l}\text { (Fish) A significant } 12 \% \text { reduction in CRC risk contrasting highest vs. } \\
\text { lowest fish consumption }\end{array}$ \\
\hline & & Randomized trial & $\begin{array}{l}\text { (Fish) No marked change of apoptosis and mitosis within the colonic crypt } \\
\text { with 6-mo intervention with oil-rich or lean fish }\end{array}$ \\
\hline \multirow{5}{*}{$\begin{array}{l}\text { Probable/ } \\
\text { less } \\
\text { consistent }\end{array}$} & \multirow{2}{*}{ Selenium } & Randomized trial & $\begin{array}{l}\text { Selenium supplementation reduced } C R C \text { risk but results were attenuated and } \\
\text { insignificant after additional years of follow-up }\end{array}$ \\
\hline & & $\begin{array}{l}\text { Meta-analysis of observational } \\
\text { and clinical trials }\end{array}$ & No association in women but significant inverse association in men \\
\hline & \multirow{2}{*}{$\begin{array}{l}\text { Dairy/ } \\
\text { calcium }\end{array}$} & $\begin{array}{l}\text { Meta-analysis of observational } \\
\text { studies }\end{array}$ & Inverse association, reduced risk with greater intake \\
\hline & & $\begin{array}{l}\text { Meta-analysis of randomized } \\
\text { trials }\end{array}$ & $\begin{array}{l}\text { Inverse association among individuals with a history of adenomas, but no } \\
\text { association otherwise }\end{array}$ \\
\hline & Vitamin D & $\begin{array}{l}\text { Meta-analysis of longitudinal } \\
\text { studies }\end{array}$ & Inverse association yet studies were limited to small sample sizes \\
\hline
\end{tabular}

Detecting the signs of colon cancer and nipping colon cancer in the bud at an early stage increases the patient's survival rate.

\section{Screening ${ }^{7,10-15}$}

Colorectal cancers may shed blood and other tissue components that can be detected in the feces long before the development of clinical symptoms. Hence screening is intended for asymptomatic individuals. Screening needs to be applied within the framework of a program that includes: primary prevention (diet and lifestyle), timely diagnostic work up with colonoscopy in those screened positive, and timely treatment (polypectomy, surgery). Any patient with symptoms or signs suggesting the presence of colorectal cancer falls outside the domain of screening and requires diagnostic workup. Several different screening tests can be used to find the polyps or colorectal cancer. Each can be used alone or in combination with each other. ${ }^{10}$

- Fecal Occult Blood Test (FOBT): Colorectal cancers may shed blood and other tissue components that can be detected in the feces. The guaiac smear test is the most common test for detecting the fecal occult blood. The guaiac test reacts to the peroxidase activity of heme. Dietary restrictions are required. The sensitivity of the test is only $50-60 \%$ for one-time use, but may be as high as $90 \%$ when it is 
used every 1-2 years over a long period of time (programmatic sensitivity). A drawback of this screening is that its effectiveness requires compliance with testing over many years.

- Fecal Immunochemical Test (FIT or iFOBT): It is a newer kind of test that also detects the occult blood in the stool. It detects hemoglobin using sensitive and specific techniques. These tests obviate the need for dietary restrictions. The optimum cut-off point for sensitivity in the immunochemical tests remains to be validated.

- Stool DNA Test (sDNA): Cancerous tumors and large polyps shed cells that contain altered DNA into the large bowel. Thus the sDNA test helps in the detection of gene mutations in the stool samples. This test gives increasing knowledge about the molecular properties of cancer. However, the optimal set of molecular markers remains to be determined, and the feasibility of such tests when applied to the general population is as yet unknown.

- Flexible Sigmoidoscopy: A slender, flexible, hollow, lighted tube is inserted through the rectum into the colon by a trained examiner. It allows the direct examination of inner surface of the large bowel up to a distance of $60 \mathrm{~cm}$ from the anal margin. This technique can detect colorectal polyps and cancers and is used to remove the polyps or take tissue samples for histological examination. Recent clinical trial results indicate that a single sigmoidoscopy screening between the ages of 55 and 64 years reduces colorectal cancer incidence by $33 \%$ and mortality by $43 \%$.

- Colonoscopy: It is the most accurate and versatile test for CRC, since it can localize and biopsy lesions throughout the large bowel, detect synchronous neoplasms and remove polyps. Colonoscopy allows direct visual examination of the entire colon and rectum. It allows the detection and removal of polyps and biopsy of cancers throughout the colon. The sensitivity for large adenomas and colorectal cancer exceeds 90\%. Colonoscopy requires full bowel preparation and sedation. Colonoscopy is the investigation of choice for screening high risk patients. Colonoscopy also has the longest rescreening interval of all forms of testing; if normal, the exam need not be repeated for 10 years. However, colonoscopy has a higher risk of complications than other form of testing, including bowel bleeding, when a polyp is removed.

- Double Contrast Barium Enema: The double-contrast barium enema (DCBE) is also called an air-contrast barium enema or a barium enema with air contrast. It may also be referred to as a lower GI series. It is basically a type of x-ray test. In this the patient receives an enema with liquid barium, followed by air enema. This creates an outline around the colon, allowing seeing the outline of colon on the X-ray. The sensitivity for detection of colorectal cancer is approximately $82 \%$ for double contrast barium enemas.

- Computed Tomographic Colonography (CTC): This imaging procedure may also be referred to as virtual colonoscopy. Thin-section helical computed-tomographic scanning of the abdomen and pelvis, followed by digital processing and interpretation of the images, can display two-dimensional and three-dimensional reconstructions of the colonic lumen. CTC technique does not require sedation. CTC is less invasive than the other screening techniques, requires no recovery time and takes 10-15 minutes for completion. Invasive cancer and polyps approximately $1 \mathrm{~cm}$ or larger in size can be detected by CTC.

- The different screening methods for colon cancer are briefed in the table 3 .

Table 3. Screening methods for colorectal cancer

\begin{tabular}{|lll|}
\hline Method & Description & Notes \\
\hline $\begin{array}{l}\text { Flexible } \\
\text { sigmoidoscopy }\end{array}$ & $\begin{array}{l}\text { Flexible, lighted, tubelike video camera inserted into } \\
\text { rectum allows visualization of entire rectum, but } \\
\text { less than half of colon }\end{array}$ & Requires bowel preparation \\
\hline Colonoscopy & $\begin{array}{l}\text { Flexible, lighted, tubelike video camera inserted into } \\
\text { rectum allows visualization of entire rectum and colon; } \\
\text { has ability to remove any identified polyps }\end{array}$ & $\begin{array}{l}\text { Requires bowel preparation; use of sedation requires patient } \\
\text { to rely on another person to drive him/her home after the } \\
\text { procedure }\end{array}$ \\
\hline $\begin{array}{l}\text { Double-contrast } \\
\text { barium enema }\end{array}$ & $\begin{array}{l}\text { Barium sulfate suspension is injected with air into } \\
\text { rectum via flexible tube; } x \text {-ray images are taken }\end{array}$ & $\begin{array}{l}\text { Requires bowel preparation; colonoscopy may be performed } \\
\text { to evaluate/remove any suspicious polyps }\end{array}$ \\
\hline CT colonography & $\begin{array}{l}\text { Patient lies within scanning machine, which rotates } \\
\text { around him/her taking cross-sectional images that } \\
\text { enable 2- or 3-dimensional visualization of colon } \\
\text { and rectum }\end{array}$ & $\begin{array}{l}\text { Requires bowel preparation; may require drinkable contrast } \\
\text { solution, as well as insertion of air into colon to improve } \\
\text { visualization; colonoscopy may be performed to evaluate/ } \\
\text { remove any suspicious polyps }\end{array}$ \\
\hline FOBT & $\begin{array}{l}\text { Patient applies stool sample (usually 3 consecutive } \\
\text { bowel movements) to test-kit cards and returns/mails } \\
\text { completed kit to medical office/laboratory }\end{array}$ & $\begin{array}{l}\text { Requires colonoscopy for positive test to determine cause of } \\
\text { bleeding; NSAIDs, aspirin, vitamin C (>250 mg/day), or red } \\
\text { meat } \leq 3 \text { days before testing interacts with accuracy; may not } \\
\text { detect nonbleeding tumors }\end{array}$ \\
\hline FIT or iFOBT & $\begin{array}{l}\text { Patient applies stool sample (usually 2-3 consecutive } \\
\text { bowel movements) to test-kit cards and returns/mails } \\
\text { completed kit to medical office/laboratory }\end{array}$ & $\begin{array}{l}\text { Requires colonoscopy for positive test to determine cause of } \\
\text { bleeding; no dietary limitations; may not detect nonbleeding } \\
\text { tumors }\end{array}$ \\
\hline
\end{tabular}




\section{Diagnosis ${ }^{7,13,16-17}$}

- Signs and Symptoms: The common symptoms of colorectal cancers are rectal bleeding, altered bowel habit, abdominal discomfort and bloating, iron deficiency anemia, unexplained weight loss, shortness of breath, angina, fatigue, nausea and vomiting.

- Blood tests: When colon cancer spreads, it can cause the chemicals in the blood to be abnormal. Common tests include complete blood cell count and blood chemistry. When colon cancer spreads, it can cause chemicals in the blood to be abnormal. An example of the chemicals that doctors look for is a high carcinoembryonic antigen (CEA) level. Non-cancer related causes of an elevated CEA include gastritis, peptic ulcer, chronic obstructive pulmonary disease, diabetes, liver disease or any acute or chronic inflammatory state. Changes in liver caused by some cancer treatments can also be detected by blood chemistry tests (liver function test). Blood cell counts indicate the normal number of blood cells. Blood cell counts are often repeated during chemotherapy since they can affect cells in the marrow that make blood.

- Imaging test: These tests help to detect whether the cancer has spread beyond the colon. Computed Tomography (CT or CAT) is the test most used for colon cancer. Other imaging tests include Magnetic Resonance Imaging (MRI), Positron Emission Tomography (PET), Ultrasound, Chest X-ray, and Angiography to see if the tumor has spread to the lungs, liver, lymph nodes or ovaries.

- Lymph node biopsy: Lymph is a clear fluid that returns fluid and protein to the blood. It travels between tissues, blood and lymph nodes in long, tube-shaped vessels. Lymph vessels and nodes are naturally found everywhere in the body, which allows colon cancer to spread far. When tumor has grown through the submucosa of the colon wall, lymph nodes are removed during surgical treatment. The nodes are then tested for cancer cells.

- Genetic tests: Genetic instability either develops through instable chromosomes (chromosomal instability, CIN; in about 80\%) or, through alterations in microsatellites [microsatellite instability (MSI, in about 15-20\%)]. To test the Lynch syndrome, the microsatellite instability is assessed. Microsatellite instability (MSI) is abnormal changes in deoxyribonucleic acid, when DNA is making a copy of its own. MSI is caused by methylated genes as an epigenetic feature called CpG Island Methylator Phenotype (CIMP). The gold standard for MSI testing is polymerase chain reaction (PCR), and the type of markers used for highest sensitivity is currently being scrutinized.

- Non-inherited changes in genes which affect the colon cancer treatment are also tested ( $K$-ras gene and $B R A F$ gene). The $K$-ras proto-oncogene encodes guanosine 5'-triphosphate (GTP) binding protein at the beginning of the MAPK signaling pathway. $K$-ras is found to be mutated in about $40 \%$ of people with colorectal cancer. People who do not have the mutated gene are said to have the "wild type" K-ras gene. Research shows that people who have the $K$-ras mutation do not respond to drugs called EGFR inhibitors, such as cetuximab (Erbitux) and panitumumab (Vectibix). Thus, EGFR inhibitors may be an option for those with a "wild type" $K$-ras gene. $B R A F$ gene encodes a serine-threonine protein kinase that is downstream of K-ras in the MAPK signaling pathway. BRAF mutations occur in $5-22 \%$ of all colorectal cancers. The most frequently reported $B R A F$ mutation is a valine-to-glutamic acid amino acid substitution. BRAF mutations are mutually exclusive with $K$-ras mutations.

- Oncotype DX colon cancer assay test is for people with stage II colon cancer. This test analyzes 12 different genes to give a "recurrence score." The score (a number between zero and 100) estimates the chance of the cancer returning after surgery. A low score indicates a low risk of recurrence, and a high score, a high risk of recurrence.

\section{Stages of Colon Cancer ${ }^{18,19}$}

Stage of disease is the most important determinant of prognosis in colorectal cancer. Once a cancer diagnosis is made, the cancer will be described by a stage and grade. Colorectal cancer staging describes the size of the tumor, how far it has grown into the colon or rectum wall, and whether the cancer has spread to lymph nodes or other places in the body past the place where it began to grow.

The American Joint Committee on Cancer (AJCC) staging classification of colorectal cancer is illustrated in the table 4 . The TNM and Dukes classification of the tumor stages are depicted in the figures 2 and 3. 


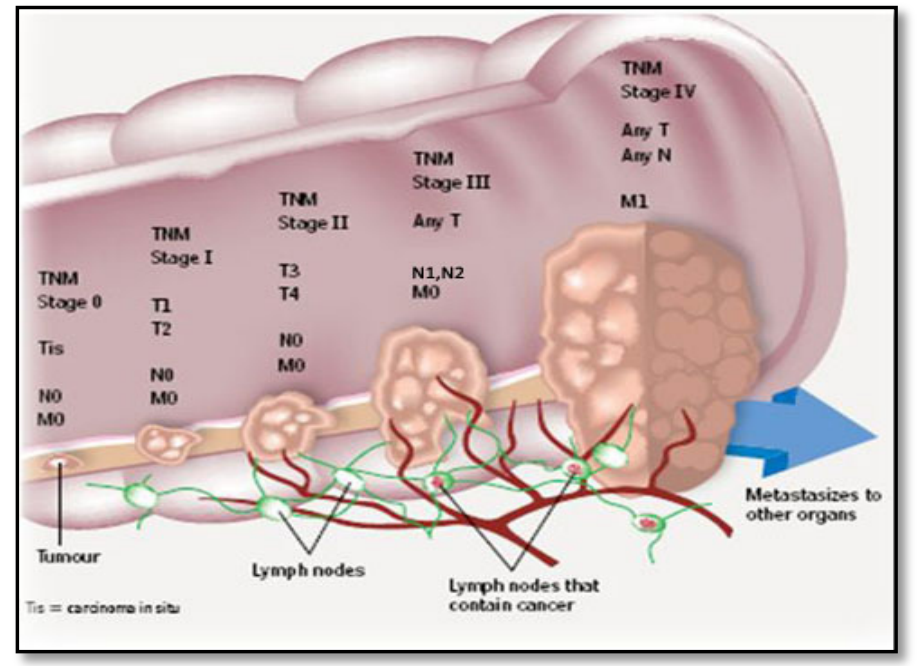

Figure 2. TNM Classification of Tumor Stages

Table 4. Staging classification of Colorectal cancer

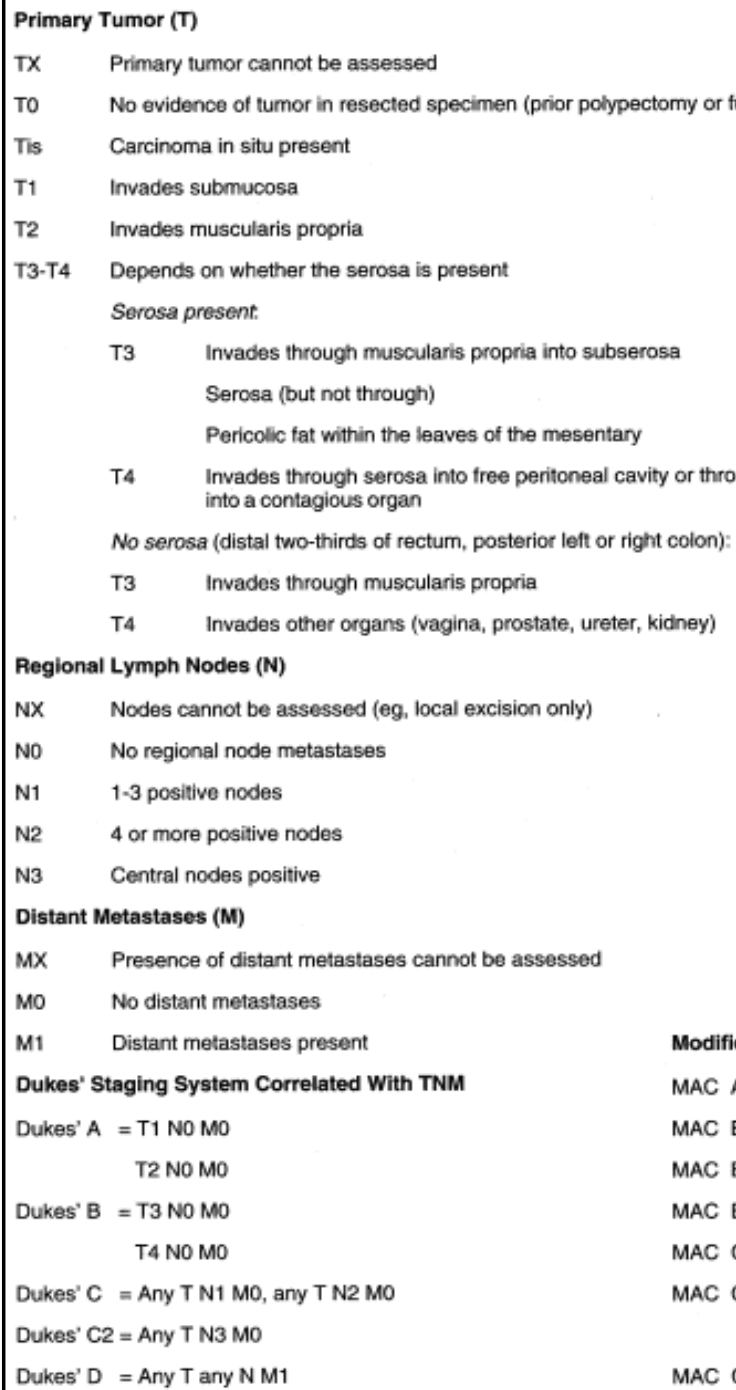

Modified Astier-Coller (MAC) System Correlated With TNM $M A C A=T 1$ NOMO

MAC B1 $=$ T2 NO MO

MAC B2 $=$ T3 NOMO, T4 NO MO

$M A C B 3=T 4$ NOMO

MAC C1 $=$ T2 N1 MO, T2 N2 MO

MAC C2 $=$ T3 N1 MO, T3 N2 MO

T4 N1 MO, T4 N2 MO

MAC C3 $=$ T4 N1 MO, T4 N2 MO 


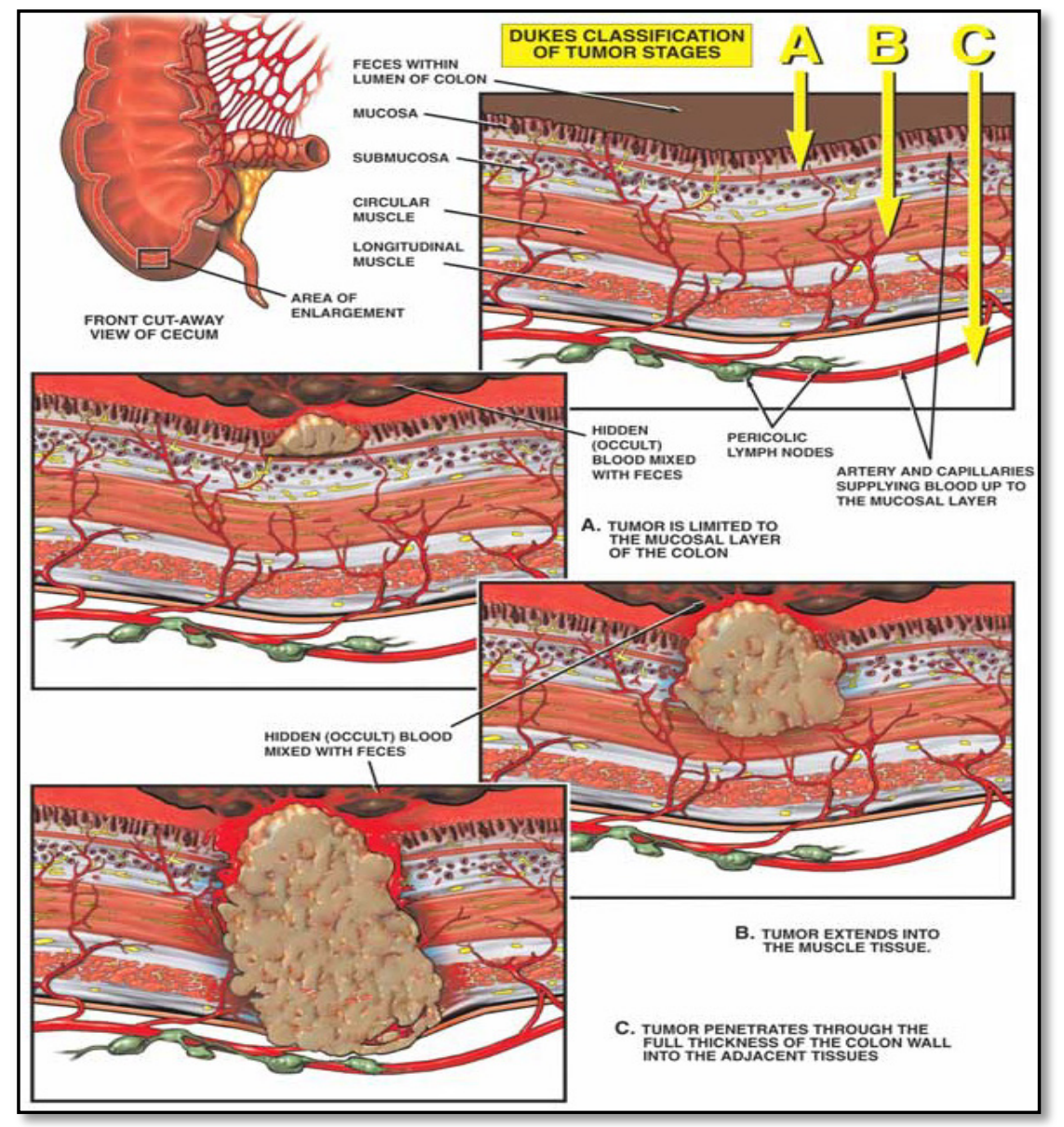

Figure 3. Dukes Classification of Tumor stages

\section{Treatment ${ }^{20-25}$}

The treatment plan for colon cancer is generally based on the state of the disease, location of the disease and the functional status of the patient. There are several terms used to describe when the treatment is given, which are shown in table 5 .

Table 5. Terms used to describe the order of treatment

\begin{tabular}{|c|c|}
\hline \multicolumn{2}{|c|}{ Terms describing the order of a treatment } \\
\hline $\begin{array}{l}\text { Primary treatment } \\
\text { Conversion treatment } \\
\text { Neo-adjuvant treatment } \\
\text { Adjuvant treatment } \\
\text { First line treatment } \\
\text { Second line treatment }\end{array}$ & $\begin{array}{l}\text { The main treatment for cancer } \\
\text { Treatments given to qualify for surgery } \\
\text { Treatments given before the primary } \\
\text { treatment } \\
\text { Treatments that follows primary } \\
\text { treatment } \\
\text { The first treatment given } \\
\text { The treatment given after the first } \\
\text { treatment fails }\end{array}$ \\
\hline
\end{tabular}

Treatment for colorectal cancer includes one or more of the following:

- Surgery: Surgery is often the main treatment for the earlier stages of colorectal cancers.

$\checkmark$ Open colectomy: A colectomy (sometimes called a hemicolectomy, partial colectomy, or segmental resection) removes part of the colon, as well as nearby lymph nodes. The surgery is referred to as an open colectomy, if it is done through a single incision in the abdomen.

$\checkmark$ Laparoscopic assisted colectomy: This newer approach to removing part of the colon and nearby lymph nodes may be an option for some earlier stage cancers. Instead of making one long incision in the abdomen, the surgeon makes several smaller incisions. One of the instruments, called a laparoscope, has a small video camera on the end, is inserted through these incisions and it allows the surgeon to see inside the abdomen. Once the diseased part of the colon has been freed, one of the incisions is made larger to allow for its removal.

$\checkmark \quad$ Polypectomy and local excision: For a polypectomy, the cancer is removed as part of the polyp, which is cut at its stalk. Local excision removes superficial cancers and a small amount of nearby tissue.

$\checkmark \quad$ Local transanal resection: Local transanal resection is done with instruments inserted through the anus, without making an opening in the skin of the abdomen. This operation cuts through all layers of the rectum to remove cancer as well as some 
surrounding normal rectal tissue, and then closes the hole in the rectal wall. This procedure can be used to remove stage I rectal cancers.

$\checkmark$ Endoscopic treatments include hot biopsy, snare polypectomy, endoscopic submucosal resection (EMR), piecemeal EMR (EPMR) and endoscopic submucosal dissection (ESD). Hot biopsy is performed cautiously in the cecum using a low amplitude and brief duration of current because the colonic wall is the thinnest and most vulnerable to transmural necrosis in this region. Snare polypectomy is chiefly applied to pedunculated and sessile lesions of 0.5 to $2.0 \mathrm{~cm}$ in diameter. Sessile polyps between 2 and $3 \mathrm{~cm}$ in diameter may be removed by snare polypectomy after creating a pseudopedicle by injecting normal saline or other solution into the polyp base. Sessile polyps more than $3 \mathrm{~cm}$ in diameter may be unamenable to conventional snare polypectomy but can be removed by sequential piecemeal polypectomy over several colonoscopies

$\checkmark \quad$ Transanal endoscopic microsurgery (TEM)

$\checkmark \quad$ Low anterior resection

$\checkmark$ Proctectomy with colo-anal anastomosis

$\checkmark$ Abdominoperineal resection

$\checkmark$ Radiofrequency ablation

$\checkmark$ Ethanol ablation

$\checkmark$ Cryosurgery

- Lymph node surgery: The surgery to remove lymph nodes is called lymphecomy. A lymphectomy is often done during a colectomy.

- Radiation therapy: During radiation therapy, high doses of special type of energy (radiation) are aimed at the area where the cancer is growing and destroy cells, making it impossible for them to grow and divide. There are two types of radiation therapy that can be used:

$\checkmark$ External beam radiation therapy, where beam of radiation is directed at the tumor.

$\checkmark$ Brachytherapy, where radioactive material is placed inside the tumor, making it possible to treat the cancer in a focused manner.

- Systemic therapy: This therapy uses drugs to treat the cancer cells that have spread through the body. Chemotherapy and targeted therapy are the systemic therapies for colon cancer. The systemic drugs used for colon cancer are shown in Table 6:

$\checkmark \quad$ Chemotherapy is the use of anti-cancer medicines that are typically given by injection, or sometimes as pills, to destroy the cancer cells.

$\checkmark$ Targeted therapy: It is a type of medication that blocks the growth of cancer cells by interfering with the specific targeted molecules needed for carcinogenesis and tumor growth rather than simply interfering with all rapidly dividing cells.

- Complementary and alternate medicine (CAM) such as vitamins, herbs, or stress reduction may be suggested as a treatment for cancer or to make feel better. CAM is a group of treatments that aren't usually given by doctors. Complementary medicines are treatments given along with usual medical treatments. Examples include acupuncture for pain management or yoga for relaxation. Alternative medicine is used in place of usual medicine.

Table 6. Systemic drugs and the drug therapy used for colon cancer

\begin{tabular}{|c|c|}
\hline Generic Name & Drug Type \\
\hline Bevacizumab & Targeted therapy \\
Capecitabine & Chemotherapy \\
Cetuximab & Targeted therapy \\
Floxuridine & Chemotherapy \\
Fluorouracil & Chemotherapy \\
Irinotecan HCl & Chemotherapy \\
Leucovorin calcium & Improves 5-FU \\
Levoleucovorin & Improves 5-FU \\
Oxaliplatin & Chemotherapy \\
Panitumumab & Targeted therapy \\
\hline
\end{tabular}

\section{Newer Treatment Options for Colorectal Cancer ${ }^{26-30}$}

- Immunotherapy: It is a type of treatment that uses the body's own immune system to fight cancer. The therapy mainly consists of stimulating the immune system to help it do its job effectively. The various types of immunotherapy include:

$\checkmark \quad$ Biological response modifiers: It includes cytokines such as interferons and interleukins. These substances do not directly destroy the cancer, but they are able to trigger the immune system to indirectly affect tumors.

$\checkmark$ Colony-stimulating factors: These are substances that stimulate the production of bone marrow cells, which include both red and white blood cells and platelets.

$\checkmark \quad$ Cancer vaccines: It uses cancer cells, parts of cells, or pure antigens to increase the immune response against cancer cells that are already in the body. Vaccines are often combined with other substances or cells called adjuvants that help boost the immune system. Several types of cancer vaccines include:

a) Tumor cell vaccine: These vaccines are made from actual cancer cells that have been removed during surgery. The cells are treated with radiation so they cannot form more tumors. The cells are then injected into the patient. The immune system recognizes antigens on these cells and attacks other cells with these antigens that are still in the body.

b) Dendritic cell vaccine: Dendritic cells are special immune cells in the body that help the immune system recognize cancer cells. They break down the cancer cells into smaller pieces so that it is visible to 
the T-cells.

c) Antigen vaccines: The antigens are usually proteins or pieces of protein called peptides. These vaccines boost the immune system by using only one antigen, rather than whole tumor cells.

$\checkmark$ Monoclonal antibodies: These are substances produced in the lab that can locate and bind to cancer cells wherever they are in the body. These antibodies can be used to see where the tumor is in the body (detection of cancer), or as therapy to deliver drugs, toxins, or radioactive material directly to a tumor. Eg: cetuximab, bevacizumab, panitumumab.

- Targeted therapy:

$\checkmark \quad$ Anti-angiogenic agents: It is a promising approach for colon cancer therapy, as it is less toxic and has a lower risk of drug resistance. Cancer cells depend on angiogenesis to obtain nutrients and oxygen for their outgrowth and metastasis. Some anti-angiogenic agents currently approved by the FDA include bevacizumab (targets VEGF-A), tyrosine kinase inhibitors sunitinib (targets VEGF and PDGF receptors) and sorafenib (targets Raf, VEGF and PDGF receptors). In this approach, tissue inhibitors of metalloproteinases (TIMPs), integrin antagonist, monoclonal antibodies, endogenous angiogenesis inhibitors (eg: Endostatin, Vasohibin- an endothelium derived negative feedback regulator of angiogenesis) are also used.

$\checkmark$ Agents targeted at EGFR:

a) Anti-EGFR antibodies: Eg. Cetuximab and panitumumab. Cetuximab is a recombinant human/ chimeric $\mathrm{IgG}_{1}$ monoclonal antibody which binds to the extracellular domain of both normal and tumor cells and competitively inhibits the binding of epidermal growth factor and other ligands. It also mediates antibody dependent cell cytotoxicity. Cetuximab was approved by the FDA for use in patients whose disease is refractory to irinotecan with tumors expressing EGFR. Panitumumab is a human IgG2 monoclonal antibody that targets EGFR. The FDA approved panitumumab for the treatment of patients with CRC that has metastasized following standard chemotherapy.

b) EGFR tyrosine kinase inhibitors: Gefitinib and erlotinib prevent ATP binding both selectively and reversibly, and autophosphorylation of EGFR tyrosine kinase.

- Apoptosis induction: Apoptosis, or programmed cell death, plays an important role in maintaining tissue homeostasis and permitting the controlled deletion of potentially harmful cells within the adult organism. Since most tumor cells have presumably disabled apoptosis to reach a malignant status, apoptosis induction represents one of the most obvious methods for cancer treatment. The inhibitor of apoptosis proteins (IAP) are a group of structurally and functionally similar proteins that regulate apoptosis, cytokinesis and signal transduction. Eg: NAIP ，c-IAP1，c-IAP2，X-linked IAP，Survivin, Apollon, Livin/ML-IAP and IAP-like protein 2 . Lapatinib improved the proapoptotic effects of tumor necrosis factor-related apoptosis-inducing ligand (TRAIL) and two TRAIL receptor agonists, the antibodies mapatumumab and lexatumumab. NS398, a cyclooxygenase-2 (COX-2)-selective inhibitor, has been reported to cause apoptosis in cancer cell lines.

- Cytotoxics: Several new cytotoxics have shown activity in metastatic CRC. These agents include pemetrexed, edotecarin and members of a newer class of nontaxane microtubule-stabilizing agents called epothilones. Pemetrexed is a multitargeted antifolate that inhibits thymidylate synthase, among other folate-dependent enzymes involved in nucleotide synthesis. Three phase II trials in metastatic CRC have been reported. Edotecarin is a novel synthetic indolocarbazole topoisomerase- I inhibitor that was evaluated in a phase II trial of second-line therapy in patients who were irinotecan-naïve. The epothilone class currently includes two compounds that have undergone phase II testing in CRC: epothilone B and ixabepilone, an epothilone B analogue.

\section{Recent Advances in Colorectal Cancer $^{31}$}

- Regorafenib prolongs the overall survival in patients with metastatic colorectal cancer.

- Second line treatment with bevacizumab extends overall survival in patients with metastatic colorectal cancer.

- Adding cetuximab to standard adjuvant chemotherapy does not improve outcomes in stage III colon cancer.

- Study identifies factors that predict which patients with metastatic colon cancer might benefit from chemotherapy.

- FDA approved cetuximab in combination with FOLFIRI chemotherapy for patients with metastatic colorectal cancer.

- FDA approved ziv-aflibercept injection in combination with FOLFIRI chemotherapy for patients with metastatic colorectal cancer.

\section{Clinical Trials ${ }^{32}$}

Ongoing researches in colorectal cancer have lead to advances in treatment and new ways to manage side effects related to treatment. Always in search of more effective treatments, many clinical trials are done to test different combinations of drugs that are already used separately to treat colorectal cancer. 
Clinical trials that are currently underway include:

- Cetuximab (Erbitux) and/or bevacizumab (Avastin) together with combination chemotherapy in treating metastatic colorectal cancer.

- Oxaliplatin (Eloxatin), leucovorin and fluorouracil with or without bevacizumab in

- treating people who had surgery for stage II colon cancer.

- Chemotherapy with or without bevacizumab in treating patients with stage II or

- stage III rectal cancer.

- Combination chemotherapy with or without bevacizumab in metastatic or locally

- advanced colorectal cancer that cannot be removed with surgery.

- Selenium to prevent recurrence of adenomatous colorectal polyps.

- Study of a statin (Rosuvastatin) to prevent polyps in patients with resected stage I or II colon cancer.

- Comparison of chemotherapy combinations (irinotecan/oxaliplatin plus 5-fluorouracil/ leucovorin with or without cetuximab) after curative resection for patients with stage III colon cancer.

- Parsatuzumab in combination with Avastin (Bevacizumab) for treating first-line metastatic colorectal cancer.

- New treatments such as panitumumab (Vectibix) (a drug similar to cetuximab) are being investigated in clinical trials as a choice treatment in colorectal cancer.

\section{Conclusion}

Colon cancer is that it usually starts from a pre-cancerous growth called a polyp and grows slowly, usually in a predictable way. It therefore can be preventable with screening, and when diagnosed at an early stage, it is often curable. Regular colorectal cancer screening or testing is one of the most powerful weapons for preventing colorectal cancer. Screening is the process of looking for cancer in people who have no symptoms of the disease. Screening needs to be applied within the framework of a program that includes: primary prevention (diet and lifestyle), timely diagnostic work up with colonoscopy in those screened positive, and timely treatment (polypectomy, surgery).

\section{REFERENCES}

[1] Risio M. The natural history of adenomas. Best Pract Res Clin Gastroentero., Vol 24, No.3, 271-280, 2010.

[2] Søreide K, Buter TC, Janssen EA, Gudlaugsson E, Skaland I, Korner H, Baak JP. Cell-cycle andapoptosis regulators (p16INK4A, p21CIP1, beta-catenin, survivin, and hTERT) and morphometry-defined MPECs predict metachronous cancer development in colorectal adenoma patients. Cell Oncol., Vol 29, No.4, 301-313, 2007.

[3] Jemal A, Bray F, Center MM, et al. Global cancer statistics. CA Cancer J Clin., Vol 61, 69, 2011.

[4] Siegel R, Naishadham D, Jemal A. Cancer statistics, 2013. CA Cancer J Clin., Vol 63, 11, 2013.

[5] Swaminathan R, Selvakumaran R, Esmy PO, et al. Cancer pattern and survival in a rural district in South India. Cancer Epidemiol., Vol 33,325-31, 2009.

[6] Yeole BB. Trends in cancer incidence in esophagus, stomach, colon, rectum and liver in males in India. Asian Pac J Cancer Prev., Vol 9, 97-100, 2008.

[7] Levin B, Liebermann DA, McFarland B, et al. screening and surveillance for the early detection of colorectal cancer and adenomatous polyps: a joint guideline from the American Cancer Society, the US Multi-Society Task Force on Colorectal cancer, and the American College of Radiology. CA Cancer J Clin., Vol 58,No.3, 130-160, 2008.

[8] Kirkegaard H, Johnsen NF, Christensen J, Frederiksen K, Overvad K, Tjonneland A. Association of adherence to lifestyle recommendations and risk of colorectal cancer: a prospective Danish cohort study. BMJ., Vol 341, c5504, 2010 .

[9] Timothy J Yeatman. Colon Cancer. Encyclopedia of Life Sciences, 1-6, 2001.

[10] Screening for Colorectal Cancer. Clinical Practical Guidelines, 2008.

[11] Colorectal Cancer Screening. World Gastroenterology Organization/ International Digestive Cancer Alliance Practical Guidelines, 2007.

[12] Screen for Life, National Colorectal Cancer Action Campaign. Centers for Disease Control and Prevention, 2009.

[13] Colon Cancer. NCCN Guidelines for Patients. National Comprehensive Cancer Network, 2012.

[14] Atkin WS, Edwards R, Kralj-Hans I, et al. Once-only flexible sigmoidoscopy screening in prevention of colorectal cancer: a multicentre randomized controlled trial. Lancet, Vol 375, No.9726, 1624-1633, 2012.

[15] Johnson CD, Chen MH, Toledano AY, et al. Accuracy of CT colonography for detection of large adenomas and cancers. $\mathrm{N}$ Engl J Med., Vol 359, No.12, 1207-1217, 2008.

[16] Garnett MJ, Marais R. Guilty as charged: B-RAF is a human oncogene. Cancer Cell, Vol 6, 313-319, 2004.

[17] Søreide K, Janssen EA, Søiland H, Kørner H, Baak JP. Microsatellite instability in colorectal cancer. Br J Surg., Vol 93, No.4, 395-406, 2006.

[18] AJCC Cancer Staging Manual (Sixth ed.). Springer-Verlag New York, Inc. 2002.

[19] Dukes CE. The classification of cancer of the rectum. Journal of Pathological Bacteriology, Vol.35, No. 3, 323, 1932.

[20] Treatment Options for Colorectal Cancer: A Guide for Patients, 2008.

[21] Kato $\mathrm{H}$ et al. Lifting of lesions during EMR of early colorectal 
cancer: implications for the assessment resectability. Endoscopy, Vol.33, 568-573, 2001.

[22] Kato H, Sakamoto T, Yamada R, Tsunoda C, Haga S. Endoscopic Mucosal Resection (EMR) for Colorectal Lesions and Lesion-lifted Condition as an Indicator of the Tumor Invasion. Ann. Cancer Res. Therap, Vol. 16, No. 1, 25-30, 2008.

[23] Dell'Abate P, Iosca A, Galimberti A, Piccolo P, Soliani P \& Foggi E. Endoscopic treatment of colorectal benign-appearing lesions $3 \mathrm{~cm}$ or larger: techniques and outcome. Dis Colon Rectum, Vol. 44, 112-118, 2001.

[24] Waye JD. New methods of polypectomy. Gastrointest Endosc Clin N Am, Vol. 7, 413-422, 1997.

[25] Weston AP, Campbell DR. Diminutive colonic polyps: histopathology, spatial distribution, concomitant significant lesions, and treatment complications. Am J Gastroenterol, Vol. 90, 24-8, 1995.

[26] R. Xu, B. Zhou, P.C.W. Fung and X. Li. Recent advances in the treatment of colon cancer. Histol Histopathol., Vol 21, $867-872,2006$

[27] Ferrara N, Gerber HP, LeCouter J. The biology of VEGF and its receptors. Nat Med., Vol 9, 669-676, 2003.

[28] Hu H, Ran Y, Zhang Y, Zhou Z, Harris SJ, et al. Antibody library-based tumor endothelial cells surface proteomic functional screen reveals migration stimulating factor as an anti-angiogenic target. Mol Cell Proteomics, Vol 8, 816-826, 2009.

[29] Wei Y, Fan T, Yu M. Inhibitor of apoptosis proteins and apoptosis. Acta Biochim Biophys Sin, Vol 40, No.4,278-288, 2008.

[30] Richard M Goldberg. Advances in the treatment of metastatic colorectal cancer. The Oncologist, Vol 10, No.3,40-48, 2005.

[31] Clinical Cancer Advances. ASCO's Annual Report on progress against Cancer 2012.

[32] www.cancer.gov/clinicaltrials 